\title{
The Influence of Zinc Oxide Eugenol (ZOE) and Glass Ionomer (GI) Base Materials on the Microhardness of Various Composite and GI Restorative Materials
}

\author{
Roee Itskovich ${ }^{1}$, Israel Lewinstein ${ }^{2}$ and Uri Zilberman ${ }^{1,3, *}$ \\ ${ }^{I}$ Faculty of Dental Medicine, Hebrew University, Hadassah, Ein Karem, Jerusalem, Israel \\ ${ }^{2}$ Department of Oral Rehabilitation, Gabriela Goldshlager School of Dental Medicine, Tel Aviv University, Tel Aviv, \\ Israel \\ ${ }^{3}$ Pediatric Dental Department, Barzilai Medical Center, Ashkelon, Israel
}

\begin{abstract}
Objective: Re-examining the well accepted concept that Zinc-Oxide-Eugenol bases (ZOE) have a negative effect on composite restoration materials microhardness, in light of the advancement in composite materials and newer publications.

Methods: Five modern composite restoration materials were used, including hybrid (Xtra-fill and Z250), micro-fill hybrid (G-aenial and Gradia-direct) and methacrylate-free restorative material (Silorane- oxirane). Two base materials were used IRM (ZOE-base) and Fuji-IX (GI-base). Samples were made using a designed mold, in which composite discs were cured on top and in close relation to base materials. Micro-hardness testing was performed using a DMH-2 microhardness tester utilizing the Knoop method.

Results: Statistic analysis demonstrated significantly better microhardness of three composite materials when IRM was used as base in comparison to control (G-aenial, Gradia direct and Filtek silorane), and no differences in two materials (Filtek universal Z250 and Voco Xtra-fil). Fuji-IX bases showed a significant positive effect on the microhardness of four composite materials, and a negative effect on one material (Voco Xtra-fill). In comparison with other tested restoration materials, both Voco Xtra-fill and Fuji-IX showed higher microhardness results $(\mathrm{P}<0.05)$.

Significance: Related to microhardness, both ZOE and GI bases can be used safely as bases under composite restorations. The results of this study together with the results published recently showed that the concept of not using ZOE or GI bases under composite must be reconsidered. Fuji IX showed microhardness results similar to the best composite material and therefore it can be used as a restorative material.
\end{abstract}

Keywords: Zinc oxide eugenol, Glass-ionomer, Composite, Microhardness, Knoop method, Fuji-IX, IRM.

\section{INTRODUCTION}

One of the most accepted and indisputable statements in restorative dentistry is that cavity bases containing ZincOxide-Eugenol (ZOE) have a negative effect on polymerization of conventional composites, yielding weaker restorations. This statement, or similar, can be found in many recent published chapters describing restorative procedures in dentistry [1-4]. The main problem with these statements in the dental manuals is that they are transferred from one edition to the next without any references. The studies on which they were probably based were those of Lingard et al. from 1981 [5] and Marshall et al. from 1982 [6]. In Lingard et al. [5] the composite materials studied were Adaptic and Concise (chemically activated composites) and the base materials were Dycal and Procal (calcium hydroxide $\mathrm{Ca}(\mathrm{OH})_{2}$

*Address correspondence to this author at the Uri Zilberman, DMD, PhDPediatric Dental Department, Barzilai Medical Center, 2nd Hahistadrut st, Ashkelon, 78278, Israel; Tel: +972 (0)8 6745854; Fax: +972 (0)8 6745238; E-mail: uri-z@smile.net.il containing bases), Cavitec (ZOE base) and Poly F (glassionomer like material). In the study of Marshall et al. [6] the composite materials examined were Heliosit with a bonding agent (light activated resin) and Isopast and Vytol (chemically activated resins), while the base materials tested were Kalzinol (ZOE), Reolit $\left(\mathrm{Ca}(\mathrm{OH})_{2}\right)$, Stailine Super EBA (ZOE modified EBA cement), Chembond (polycarboxylate cement) and Poly F (glass-ionomer like material). The conclusion from both papers was that chemically activated composites were affected by both ZOE containing base and GI base, and the bonding agent, when applied between the light activated composite and the base material minimized the effect. During the early 90's, Hotz et al. [7] and Lussi and Hotz [8] examined the effect of base materials on chemically and light activated composites. They examined the effect of Nobetec (ZOE containing base) on six chemically and light cured composites. The results showed that on 5 out of 6 composites, the ZOE had no effect on polymerization as measured by microhardness. When calcium hydroxide containing liners (Dycal and Alkaliner) and glass-ionomer bases (Ketac-Bond and Vitrebond) were placed beneath the com- 
Table 1. The restoration materials

\begin{tabular}{|c|c|c|c|}
\hline Chemistry & Classification & Restoration material $\backslash$ Manufacturer & Code \\
\hline $\begin{array}{l}\text { Siloxane } \\
\text { Oxirane }\end{array}$ & $\begin{array}{l}\text { Micro-hybrid non-methacrylate com- } \\
\text { posite }\end{array}$ & $\begin{array}{c}\text { Filtek Silorane } \backslash \\
\text { 3M ESPE Co., St. Paul, MN, USA }\end{array}$ & Silorane \\
\hline UDMA & Micro-fill Hybrid composite & $\begin{array}{c}\text { G-aenial } \backslash \\
\text { GC Co. Tokyo, Japan }\end{array}$ & G-aenia \\
\hline UDMA & Micro-fill Hybrid composite & $\begin{array}{l}\text { Gradia Direct anterior } \backslash \\
\text { GC Co. Tokyo, Japan }\end{array}$ & Gradia \\
\hline $\begin{array}{c}\text { Bis-GMA } \\
\text { UDMA, TEGDMA }\end{array}$ & Hybrid composite & $\begin{array}{c}\text { Xtra-fill } \backslash \\
\text { VOCO Co. Cuxhaven, Germany }\end{array}$ & Xtra-fill \\
\hline $\begin{array}{l}\text { UDMA, Bis-EMA } \\
\text { TEGDMA }\end{array}$ & Hybrid composite & $\begin{array}{c}\text { Filtek Z250 Universal Restorative } \backslash 3 \text { M ESPE Co., } \\
\text { St. Paul, MN, USA }\end{array}$ & $\mathrm{Z} 250$ \\
\hline Fluoro Aluminosilicates Glass & Glass-Ionomer & $\begin{array}{c}\text { GC Fuji-IX } \backslash \\
\text { GC Co. Tokyo, Japan }\end{array}$ & Fuji-IX \\
\hline
\end{tabular}

Table 2. The base materials

\begin{tabular}{|c|c|c|}
\hline Type & Base Material \Manufacturer & Code \\
\hline \hline Reinforced ZOE & IRM $^{\mathrm{TM}} \backslash$ & IRM \\
GI & DENTSPLY Milford, DE, USA & Fuji-IX \\
\hline
\end{tabular}

posites, a reduction in microhardness was observed in the area adjacent to the tested composite materials. Furthermore, as recent as 2010, He et al. [9] examined the elastic modulus and microhardness of composite placed above ZOE base. Their conclusion was that the ZOE base affects the composite microhardness and elastic modulus to a distance of only 100 microns from the interface, and so it can be a suitable material to be used under modern composites. Although the more recent results for ZOE containing bases show that they can be used under composites, the perception that they affect polymerization has not been changed, while the results showing that GI bases also affect polymerization $[1,2,8]$ are not published in the dental manuals. And still, IRM is the most frequently used temporary restorative material in endodontics and general practice. Moreover, some dental protocols even advocate the use of GI bases together with composite materials as in sandwich restoration technique [10, $11]$.

In modern dentistry, new composites are introduced periodically, with improved wear resistance, improved shrinkage and better polymerization. Even the basic matrix material has been changed with the release of Silorane (epoxides systemoxirane) by $3 \mathrm{M} / \mathrm{ESPE}$ [12].

Based on the new data and the improvements made in composite restorative materials, the aims of the present study were: a. To evaluate the effect of a ZOE containing base on different composite materials in use today, b. To evaluate the effect of GI base on the same composites, c. To compare the microhardness of GI restorative material to that of composites and finally $d$. To analyze the effect of a ZOE containing base on GI used as a restorative material.

\section{MATERIALS AND METHODS}

Materials: One glass ionomer (Fuji IX) and five composite restoration materials, two hybrid materials (Xtra-fill and Z250), two micro-fill hybrid materials (G-aenial and Gradia Direct) and one non-methacrylate micro hybrid material (Silorane) were used (Table 1). Two types of base materials were tested: Reinforced Zinc Oxide Eugenol (IRM) and Glass-Ionomer (Fuji IX) (Table 2).

Instruments: Two custom-made plastic molds were manufactured, in which the composite and GI samples were prepared. Each mold contained 10 wells, $2 \mathrm{~mm}$ in depth and $10 \mathrm{~mm}$ in diameter, with conversed profiles for an easy removal of the samples. All composite samples were cured using a SPETRUM 800 by Dentsply halogen based lightcuring device. This device is equipped with an output sensor and can be calibrated to the desired power setting. Standard GI delivery system and an amalgamator were used for the activation and delivering of Fuji-IX capsules. All the samples' microhardness properties were tested using a DMH-2 microhardness tester (Matsuzawa Seiki Co. Tokyo, Japan), utilizing the Knoop testing method [5-8].

Samples preparation (Fig. 1): Both slabs were sprayed with a non-stick silicone spray to prevent the materials from 

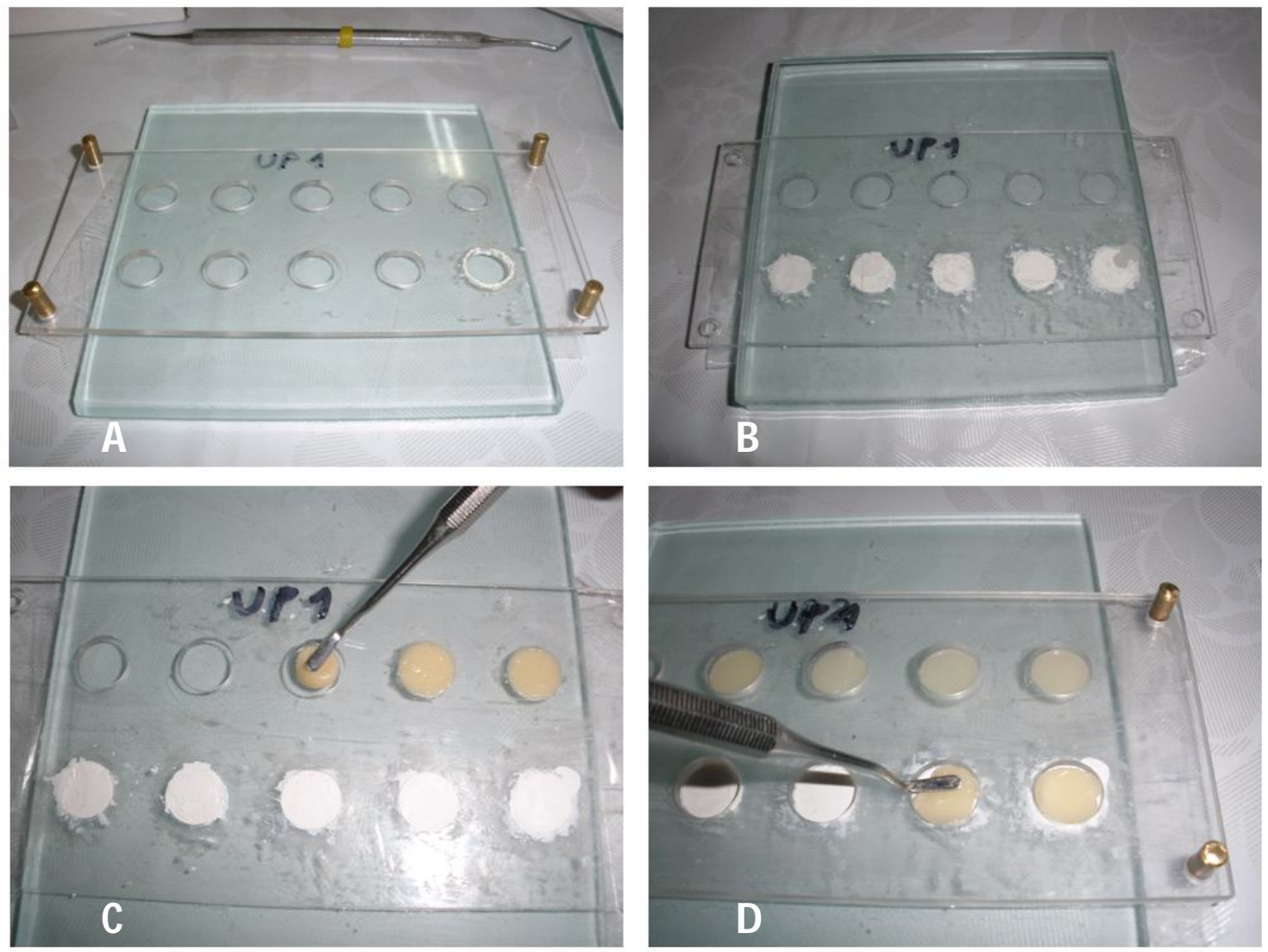

Note: A: The first mold is placed on a glass slab.

B: IRM was packed into wells in the first mold.

C: Composite restoration material being packed into wells in the first mold.

D: composite restoration material being packed into wells in the second

mold.

Fig. (1). The sample manufacturing process.

sticking and any excess spray fluids were wiped before being attached to the molds. The first mold was fixed to a mixing glass slab; IRM was mixed in accordance with the manufacturer instructions and packed into 5 wells on the lower row. A second glass slab was placed on top of the base samples, in order to achieve a smooth IRM base disc surface. IRM was left to set for 15 minutes to ensure full setting, as early removal of the covering slab had caused a rough surface on the base material. Composite restoration material was packed into the upper line of 5 empty wells, covered with the second glass slab and cured in accordance with the manufacturer's instructions. Next, the covering slab was removed and the second mold was placed and fixed on top of the first, using the designed metal pins. The same composite material was packed into the 5 wells lying directly on top of the IRM filled wells, and cured in accordance with the manufacturer instructions. The entire process is illustrated in Fig. (1). This process was repeated separately for each restoration material and then again, using Glass Ionomer as the base material.
The GI samples were also placed over IRM filled wells and tested for hardness as a restorative material. All GI samples were left to set in accordance with the manufacturer's manual before removing the covering slab.

Sample handling and processing: All restoration materials discs were removed from the molds and kept in Petri dishes padded with cotton wool pads soaked in a $0.1 \%$ thymol solution in order to prevent from bacterial growth [13]. The samples were polished using carbide paper discs up to 1200 grit (dry conditions). The MIH micro-hardness tester requires that examined samples should be parallel to the device surface; failing to provide parallelism may lead to the creation of a partial imprint by the indenter and an unreliable measurement. In order to achieve parallelism, heated compound wax was placed on glass slides and sample discs were embedded in it, then the samples were pressed using mechanical pressing clamps until the wax was set and parallelism was achieved. 
Table 3. Mean microhardness value for each restoration material examined, with regard to the different bases used and the control samples (no base).

\begin{tabular}{|c|c|c|c|c|}
\hline Restoration Material & Base & Mean (KHN) & SD & $\mathbf{N}$ \\
\hline \multirow{2}{*}{ Filtek universal z250 } & No base & 107.35 & 3.92 & 15 \\
\hline & Fuji-IX & $101.01 * *$ & 3.59 & 15 \\
\hline \multirow{2}{*}{ Voco Xtra-fil } & No base & 84.38 & 9.43 & 18 \\
\hline & Fuji-IX & $92.97 * *$ & 7.35 & 15 \\
\hline \multirow[b]{2}{*}{ G-aenial } & No base & 182.31 & 10.32 & 16 \\
\hline & IRM & $169.98 *, * * *$ & 21.16 & 20 \\
\hline \multirow[t]{2}{*}{ Gradia direct } & IRM & $169.12 *, * * *$ & 18.49 & 20 \\
\hline & Fuji-IX & $150.32 * *$ & 5.04 & 15 \\
\hline \multirow{3}{*}{ Filtek silorane } & No base & 123.17 & 3.91 & 15 \\
\hline & IRM & $119.36^{*}$ & 2.97 & 15 \\
\hline & Fuji-IX & $117.78^{* *}$ & 3.09 & 15 \\
\hline \multirow{2}{*}{ Fuji-IX } & No base & 92.38 & 6.87 & 20 \\
\hline & IRM & 95.84 & 5.88 & 16 \\
\hline
\end{tabular}

Note: $*=\mathrm{P}<0.05$ in comparison with no base

$* *=\mathrm{P}<0.01$ in comparison with no base

$* * *=\mathrm{P}<0.01$ in comparison with Fuji-IX as base

Micro-hardness measurement: Five indentations were made on each sample disc; in its center and in four other locations, so that uneven curing deviations could be detected and taken into account. The load used was $50 \mathrm{~g}[9,13]$ and was applied for 15 seconds. The Knoop method was chosen due to its more preferable characteristics [14].

Statistical methods: In order to examine the study hypothesis, two different statistical analyses were used: a. student's T-test was used to compare the microhardness results between the control and IRM or Fuji-IX as base and between the two bases, and b. a bi-factorial variance full factorial analysis was applied, using the SPSS statistical software version 18. Significance was established if the $\mathrm{P}$ value was less than $5 \%$.

\section{RESULTS}

Table 3 illustrates the microhardness values in KHN for each restorative material without base material (control) and with ZOE or GI as bases. The lowest indentation values (highest microhardness) were observed for the hybrid composites, followed by the non-methacrylate composite, while the micro fill hybrid composites showed the highest values (lowest microhardness). The GI control showed microhard- ness results similar to the hybrid composites. When cured over ZOE base (IRM) the microhardness results of 3 hybrid composites showed improved results (G-aenial, Gradia direct and Filtek silorane $\mathrm{P}<0.05$ ), and for two composites no significant differences were observed (Filtek universal z250 and Voco Xtra-fil). No significant differences were found for Fuji IX as control or over ZOE base. When GI was used as base, three of the hybrid composites (Filtek universal z250, G-aenial, Gradia direct) and the non-methacrylate based composite (Filtek silorane) showed significantly better results and only for Voco Xtra-fill the results were significantly higher $(\mathrm{P}<0.01)$ in comparison to that of the control.

A statistical comparison of the differences in microhardness between the restorative materials was performed (Table 4). The differences in microhardness between all composite materials showed statistical significance $(\mathrm{P}<0.001)$. GI restorative material showed statistical significant differences from most composite materials. GI microhardness results were similar to the hybrid composite (Voco Xtra-fil), which is the best composite in terms of microhardness.

Graph 1 illustrates the differences between the composites and Fuji IX, and the effect of the different bases on the restorative materials. 
Table 4. Differences of mean microhardness values of each restorative material in comparison to all other materials tested

\begin{tabular}{|c|c|c|c|}
\hline (I) Restoration material & (J) Restoration material & Mean Difference (I-J) & St Error \\
\hline \multirow{5}{*}{ Filtek universal z250 } & Voco Xtra-fil & $18.27 *$ & 1.92 \\
\hline & G-aenial & $-54.78^{*}$ & 1.89 \\
\hline & Gradia direct & $-63.29 *$ & 1.99 \\
\hline & Filtek silorane & $-14.60 *$ & 2.08 \\
\hline & Fuji-IX & $11.72 *$ & 2.16 \\
\hline \multirow{4}{*}{ Voco Xtra-fil } & G-aenial & $-73.05^{*}$ & 1.85 \\
\hline & Gradia direct & $-81.57 *$ & 1.96 \\
\hline & Filtek silorane & $-32.87^{*}$ & 2.05 \\
\hline & Fuji-IX & -6.54 & 2.13 \\
\hline \multirow{3}{*}{ G-aenial } & Gradia direct & $-8.51^{*}$ & 1.93 \\
\hline & Filtek silorane & $40.18^{*}$ & 2.03 \\
\hline & Fuji-IX & $66.51 *$ & 2.11 \\
\hline \multirow{2}{*}{ Gradia direct } & Filtek silorane & $48.69^{*}$ & 2.12 \\
\hline & Fuji-IX & $75.02 *$ & 2.20 \\
\hline Filtek silorane & Fuji-IX & $26.33 *$ & 2.29 \\
\hline
\end{tabular}

Note: $*=\mathrm{P}<0.001$

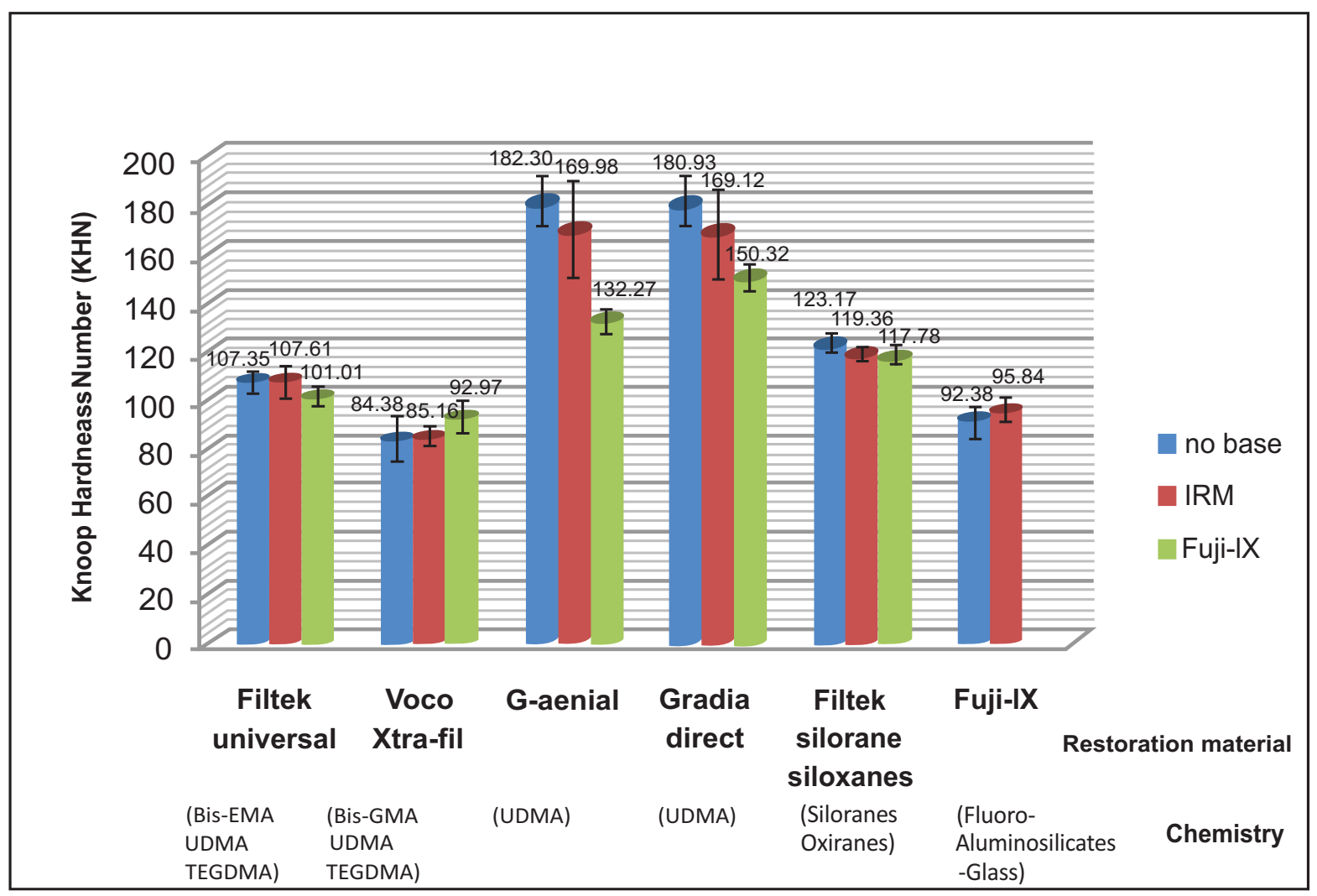

Graph (1). Differences in mean microhardness values (KHN) for all the restorative materials tested and the effect of different bases. 


\section{DISCUSSION}

The aim of this study was to re-examine the statement that ZOE bases affect the microhardness of composite materials, by reducing polymerization. The first researches on which this statement was based were conducted some 30 years ago, mainly utilizing chemically activated composites and bases that are not found today on the dental market [5, 6]. And even then, the authors concluded that for composite materials that were light activated the application of the bonding material between the ZOE base and the composite minimized the effect of ZOE on polymerization [6]. Newer publications showed no or minimal effect of eugenol containing bases on bond strength of adhesive systems and composites polymerization [15-17]. The self etching system (Adper SE plus by 3M/ESPE, St Paul, MN, USA) was significantly affected by eugenol containing bases, while on total etch system (Clear fill SE bond by Kuraray Medical, Japan) eugenol had no effect on the bond strength $[18,19]$. The effect of eugenol on different bonding systems can be related to the chemical composition of these systems. The hypothesis is that eugenol reacts with free radicals, thereby inhibiting the polymerization of methacrylate monomers. The chemical effect of eugenol on methyl methacrylate polymerization was studied in 1997 [20], using chemical activators of polymerization, benzoyl peroxide (BPO) and 2,2'azobisisobutyronitrile (AIBN). These activators were used for chemically activated composite materials that are not common on the market today. The new composite materials polymerization is induced by photoinitiators, mainly camphoroquinone (CQ). In the present study, microhardness of different light cured composite materials was examined. The initiator in all the materials examined was a photoinitiator, CQ. The best microhardness results were observed for the hybrid composites and the GI, while both bases, ZOE and GI, showed no deteriorating effect on the microhardness. Statistical analysis of the data demonstrates that the hardness of the restoration materials was not affected or positively affected by the use of base material. When all the samples cured over IRM had been compared to the control samples, it was observed that the IRM affected positively the microhardness of three of the composites tested, similar to the results of He et al. [9]. Fuji IX had a significant effect on four of the composites and only for Voco Xtra-fill it showed poorer results.

The extent of conversion of monomers to polymers by light activation is between 55-75\% [21], implicating that 25$45 \%$ of un-polymerized monomers can be found in the activated composite materials. It may be postulated that GI, when used as a base material, enhances the polymerization of the composites or extracts of non-polymerized monomers from the composite material. In both scenarios, the strength of the material is increased and the microhardness results will be higher. More studies are needed to fully understand the effect of ZOE or GI bases on the polymerization process of different composite resins and how GI bases enhance the polymerization.

When compared with other composite restoration materials, Fuji-IX when used as a restorative material has performed better than most composite materials on the microhardness test, except for Voco Xtra-fill. Voco Xtra-fill has
$85 \%$ of filler in its' compound, making it harder than the other composites, yet the Fuji-IX showed similar microhardness results [22-25]. Related to microhardness test, IRM can be used safely underneath composite restorations or GI restorations.

\section{CONCLUSIONS}

With the limits of this study, the hypothesis that ZOE has a negative effect on microhardness of composite restorative materials was not confirmed.

Different bases (ZOE or GI) showed significant effect on most of the composite materials and increased their microhardness. The only material negatively affected by the use of Fuji IX as base was Voco Xtra-fill.

Glass ionomer (Fuji IX) showed high microhardness values comparable to the composite materials and so it can be used in restorative dentistry.

\section{CONFLICT OF INTEREST}

The authors confirm that this article content has no conflicts of interest.

\section{ACKNOWLEDGEMENTS}

Based on a thesis submitted to the School of Dental Medicine, Hebrew University Jerusalem, in partial fulfillment of the requirements for the DMD degree.

\section{REFERENCES}

[1] Donly KJ, Segura A. Dental materials. In: Pinkham, Casamassimo, Fields, McTigue and Nowak, Eds. Pediatric dentistry. $4^{\text {th }}$ ed. Elsevier Saunders: St. Louis 2005; p. 327.

[2] O'Brien WJ. Phenolate-Based cements. In: O'Brien WJ, Ed. Dental materials and their selection. $3^{\text {rd }}$ ed. Quintessence: Chicago 2002; p. 139.

[3] McDonald RE, Avery DR, Dean JA. Dental materials. In: McDonald RE, Avery DR, Dean JA, Eds. Dentistry for the child and adolescent $8^{\text {th }}$ ed. Mosby, St. Louis Missouri 2007; p. 343.

[4] Stewart RE, Barber TK, Troutman KC, Wei SHY. Filled composite restorative resins. In: Stewart RE, Barber TK, Troutman KC, Wei SHY, Eds. Pediatric dentistry scientific foundations and clinical practice. $2^{\text {nd }}$ ed. Mosby: St. Louis, Missouri 1982; p. 891.

[5] Linard GL, Davies EH, von Fraunhofer JA. The interaction between lining materials and composite resin restorative materials. J Oral Rehabil 1981; 8(2): 121-9.

[6] Marshall SJ, Marshall GW, Harcourt JK. The influence of various cavity bases on the micro-hardness of composites. Aust Dent J 1982; 27(5): 291-5.

[7] Hotz P, Schlatter D, Lussi AR. The modification of the polymerization of composite materials by eugenol-containing temporary fillings. Schweiz Monatsschr Zahnmed 1992; 102(12): 1461-6.

[8] Lussi AR, Hotz P. The effect of different liner materials on the polymerization of composites. Schweiz Monatsschr Zahnmed 1994; 104(7): 854-8.

[9] He LH, Purton DG, Swain MV. A suitable base material for composite resin restoration: zinc oxide eugenol. J Dent 2010; 38(4) 290-5.

[10] Suzuki M, Jordan RE. Glass ionomer-composite sandwich technique. J Am Dent Assoc 1990; 120(1): 5-7.

[11] Friedl KH, Schmalz G, Hiller KA, Mortazavi F. Marginal adaption of composite restorations versus hybrid ionomer / composite sandwich restorations. Oper Dent 1997; 22(1): 21-9.

[12] Gao BT, Lin H, Zheng G, Xu YX, Yang JL. Comparison between a silorane-based composite and methacrylate-based composites: 
shrinkage characteristics, thermal properties, gel point and vitrification point. Dent Mater J 2012; 31(1): 76-85.

[13] D’Alpino PH, Bechtold J, dos Santos PJ, et al. Methacrylate- and silorane based- composite restorations: Hardness, depth of cure and interfacial gap formation as a function of the energy dose. Dental Mater 2011; 27(11): 1162-9.

[14] Giannakopoulos AE, Zisis T. Analysis of Knoop indentation. Int J Solids Struct 2011; 48(4): 175-90.

[15] Schwartzer E, Collares FM, Ogliari FA, Leitune VCB, Werner S SM. Influence of zinc oxide-eugenol temporary cement on bond strength of all-in-one adhesive system to bovine dentin. J Oral Sci 2007; 6(23): 1423-7.

[16] Delgado V, Lafluenta D. Microhardness of composites cured over eugenol-contaminated dentin. Int. J Dent 2011; 10(2): 50-5.

[17] Souza-Junior EJ, Bueno VCPS, Dias CTS, Paulillo LAMS. Effect of endodontic sealer and resin luting strategies on pull-out bond strength of glass fiber posts to dentin. Acta Odontol Latinoam 2010; 23(3): 216-21.

[18] Silva JPL, Queiroz DM, Azevedo LH, et al. Effect of eugenol exposure time and post-removal delay on the bond strencth of a self-etching adhesive to dentine. Ope Dent 2011;36(1): 66-71.
[19] Sevimay M, Bulbul M, Ister E. Effect of temporary cement and adhesive liner on the bond strength of Ni-Cr to dentin. SU Dishek Fak Der 2008; 17(3): 190-7.

[20] Fujisawa S, Kadoma Y. Action of eugenol as a retarder against polymerization of methyl methacrylate by benzoyl peroxide. Biomaterials 1997; 18(9): 701-3.

[21] Bakopoulou A, Papadopoulos T, Garefis P. Molecular toxicology of substances released from resin-based dental restorative materials. Int J Mol Sci 2009; 10(9): 3861-99.

[22] Kleverlaan CJ, Van Duinen RNB, De Gee AJ, Feilzer AJ. Mechanical properties of glass ionomer cements affected by different curing methods. Dent Mater 2004; 20(1): 45-50.

[23] Towler MR, Bushby AJ, Billington RW, Hill RG. A preliminary comparison of the mechanical properties of chemically cured and ultrasonically cured glass ionomer cements, using nano-indentation techniques. Biomaterials 2001; 22(11): 1401-6.

[24] Van Duinen RNB, Kleverlaan CJ, De Gee AJ, Feilzer A. Early and long-term wear of 'fast-set' conventional glass-ionomer cements. Dental Mater 2005; 21(8): 716-20.

[25] Baloch FA, Mirza AJ, Baloch D. An in-vitro study to compare the microhardness of glass ionomer cement set conventually versus set under ultrasonic waves. Int J Health Sci 2010; 4(2): 149-55.

(C) Itskovich et al.; Licensee Bentham Open.

This is an open access article licensed under the terms of the Creative Commons Attribution Non-Commercial License (http://creativecommons.org/licenses/by-nc/3.0/) which permits unrestricted, non-commercial use, distribution and reproduction in any medium, provided the work is properly cited. 